\title{
Optimal Control of Delay Differential Equations
}

\author{
R.A. Raji ${ }^{1}$, M.O. Oke ${ }^{2}$ and O. A. Adewumi ${ }^{3}$ \\ ${ }^{1}$ Department of Mathematics \& Statistics, Osun State Polytechnic, P.M.B 301, Iree, Osun State, Nigeria \\ ${ }^{2}$ Department of Electrical \& Electronic Engineering, Ekiti State University, P.M.B 5363, Ado - Ekiti, Nigeria \\ ${ }^{3}$ Department of Mathematics, University of Ilorin, P.M.B 1515, Ilorin, Nigeria
}

\begin{abstract}
Control theory has developed rapidly over the past few decades and it is now established as an important area of contemporary applied mathematics. Optimal control problem is a mathematical programming problem involving a number of stages where each stage evolves from the previous stage in a prescribed manner. In this paper, we are concerned with optimal control of delay differential equations whose costs functional are quadratic and whose state variables are governed by linear delay differential equations. We now used the multiplier method in solving the resulting problem.
\end{abstract}

Keywords: Bio-Mathematics, Delay Differential Equations, Multiplier Method, Optimal Control

\section{Introduction}

Delay differential equations differ from ordinary differential equations in that the derivative at any time depends on the solution at the prior times. The manner in which the properties of systems of delay differential equations differ from those of systems of ordinary differential equations has been and remains an active area of research, Martin and Ruan (2001), Raghothama and Narayanan (2002). Additional information is required to specify a system of delay differential equations because the derivatives depend on the solution at the previous time. It is necessary to provide an initial history function to specify the value of the solution before time $t=0$. In many common models the history is a common vector but non constant history functions are encountered routinely.

A lot of research works have been carried out on delay differential equations. Neves and Feldstein (1976) characterized the tree of derivative discontinuity times for state dependent delay differential equations as the zeros with odd multiplicity of equations. Wright (1961) studied a model for the distribution of primes in the form of $x^{\prime}(t)=-a x(t-1)(1+x(t))$ while Cunningham (1954) applied variants of this equation as models in the theory of growth of single species of organisms in an ecological setting. Volterar (1928) used the following equations to describe his predator prey models which is stated as $x^{\prime}(t)=\left\{-e_{1}-k_{1} y(t)-\int_{-r}^{0} f_{1}(\theta) y(t+\theta) d \theta\right\} x(t) \quad$ and $y^{\prime}(t)=\left\{-e_{1}+k_{2} x(t)+\int_{-r}^{0} f_{2}(\theta) x(t+\theta) d \theta\right\} y(t)$. Where $\mathrm{x}$ and $\mathrm{y}$ denote the number of prey and predators respectively. Wangesky and Cunningham (1957) established their predator prey models by employing the following equations $x^{\prime}(t)=\frac{1}{m}\{\alpha x(t)(m-x(t))\}-b x(t) y(t) \quad$ and $y^{\prime}(t)=\{\beta y(t)+c x(t-r) y(t-r)\}$. Banks and Burns (1978) investigated certain theory of plants by using the model $\alpha^{\prime}(t)=-k \int_{1}^{\infty} f(\theta) \operatorname{Sin} \alpha\left(t-\theta-t_{0}\right) d \theta$. Where $\alpha$ denotes the angle that the top of the plant makes with the real axis. Yorke (1969) applied the following model to describe the spread of measles in a metropolitan area $S^{\prime}(t)=-\beta(t) S(t)[2 \sigma+S(t-14)-S(t-12)]+\sigma$. Where $S(t)$ denotes the number of susceptible individuals at time $t, \sigma$ is the rate at which individuals enter the population, $\beta(t)$ is the population function and an individual exposed at time $t$ is infectious within the time (t-14, t-12). Optimal control problem is usually described by the control and the state variables. The control variables govern the evolution of the system from one stage to the other and the state variables describe the behaviour of the system in any stage. In this paper, we considered the optimal control of delay differential equations.

\section{Materials and Methods}

We will use the multiplier method to solve a class of optimal control problems governed by delay differential equations (with delay in $\mathrm{x}$ ).

An optimal control of delay differential equation problem can be posed as

$\operatorname{Min} \int_{0}^{1}\left[a x^{2}(t)+b u^{2}(t)\right] d t$ 
Subject to the constraint

$$
\dot{x}(t)=c_{1} x(t)+c_{2} x(t-r)+d u(t)
$$

where $x$ and $u$ are the state and control vectors respectively. $c_{1}, c_{2}$ and $d$ are constant matrices. $a$ and $b$ are symmetric positive definite matrices.

We need to obtain a control vector $u(t)$ which will minimize the quadratic functional in (1) and satisfy the constraint in (2).

\section{Example 1}

\section{Main Results}

Let us consider the minimization of $\varphi(u)=\frac{1}{2} \int_{0}^{2}\left[x^{2}(t)+u^{2}(t)\right] d t$

Subject to the constraint

$$
\dot{x}(t)=x(t-1)+u(t), x(0)=1 \text {. }
$$

Using a fixed penalty constant parameter $\mu=1.5$ and discretization in time space carried out over equally spaced time intervals, we have the result in table 1 and if $\mu=2.0$, we have the result in table 2 .

Table 1: Results for Example 1 with $\underline{\mu=1.5}$

\begin{tabular}{|l|l|l|l|l|l|}
\hline Time & $\mathrm{x}(\mathrm{t})$ & $\mathrm{u}(\mathrm{t})$ & Objective & Functional & Iteration \\
\hline 0.0 & 1.000000 & -1.685831 & 1.921014 & 2.796060 & 4 \\
\hline 0.2 & 0.863177 & -0.922939 & 0.804415 & 1.376820 & \\
\hline 0.4 & 0.238075 & -1.555254 & 1.237748 & 2.121180 & \\
\hline 0.6 & 0.345286 & -1.012792 & 0.572485 & 1.067980 & \\
\hline 0.8 & 0.443436 & -0.752812 & 0.382084 & 0.669330 & \\
\hline 1.0 & 0.520746 & -0.617863 & 0.326465 & 0.476130 & \\
\hline 1.2 & 0.577690 & -0.486093 & 0.285000 & 0.319870 & \\
\hline 1.4 & 0.593717 & $-3.4722 \mathrm{E}-02$ & 0.176852 & 0.177110 & \\
\hline 1.6 & 0.613263 & $-7.0793 \mathrm{E}-02$ & 0.190551 & 0.190880 & \\
\hline 1.8 & 0.620612 & -0.179907 & 0.208762 & 0.218600 & \\
\hline 2.0 & 0.390486 & $-1.3634 \mathrm{E}-02$ & $7.6332 \mathrm{E}-02$ & $7.72454 \mathrm{E}-02$ & \\
\hline
\end{tabular}

Table 2: Results for Example 1 with $\mu=2.0$

\begin{tabular}{|l|l|l|l|l|l|}
\hline Time & $\mathrm{x}(\mathrm{t})$ & $\mathrm{u}(\mathrm{t})$ & Objective & Functional & Iteration \\
\hline 0.0 & 1.000000 & -1.685831 & 1.921014 & 2.796060 & 4 \\
\hline 0.2 & 0.850211 & -1.040107 & 0.902340 & 1.366850 & \\
\hline 0.4 & 0.229473 & -1.607764 & 1.318782 & 2.051210 & \\
\hline 0.6 & 0.339108 & -1.062635 & 0.622094 & 1.012610 & \\
\hline 0.8 & 0.440610 & -0.793462 & 0.411855 & 0.628930 & \\
\hline 1.0 & 0.519820 & -0.642129 & 0.341271 & 0.456099 & \\
\hline 1.2 & 0.580915 & -0.486202 & 0.286927 & 0.315127 & \\
\hline 1.4 & 0.593717 & $-3.4722 \mathrm{E}-02$ & 0.176852 & 0.177118 & \\
\hline 1.6 & 0.613262 & $-7.0793 \mathrm{E}-02$ & 0.190551 & 0.190880 & \\
\hline 1.8 & 0.620611 & 0.179907 & 0.208762 & 0.218600 & \\
\hline 2.0 & 0.386696 & $-1.2279 \mathrm{E}-02$ & $7.4843 \mathrm{E}-02$ & $7.5640 \mathrm{E}-02$ & \\
\hline
\end{tabular}

\section{Example 2}

We next consider the minimization of

$$
\int_{0}^{1}\left[2 x^{2}(t)+u^{2}(t)\right] d t
$$

Subject to the constraint

$$
\dot{x}(t)=6 x(t)+5 x(t-0.2)+20 u(t)
$$

On using the method of multiplier, we have our results as tabulated in table 3 
Table 3: Results for Example 2.

\begin{tabular}{|l|l|l|l|l|l|}
\hline $\mathrm{M}$ & Mode & Cycle & $\begin{array}{l}\text { Iteration } \\
\text { Number }\end{array}$ & $\begin{array}{l}\text { Objective } \\
\text { Functional }\end{array}$ & $\left\|\varphi\left(x_{k,}, u_{k}\right)\right\|^{2}$ \\
\hline 10 & 1 & - & 4 & 1.66370 & $5.9730 \mathrm{E}-03$ \\
& $\mathrm{C}$ & 2 & 1 & 1.66190 & $5.4707 \mathrm{E}-06$ \\
\hline 20 & 1 & - & 5 & 1.66420 & $6.2450 \mathrm{E}-03$ \\
& $\mathrm{C}$ & 2 & 1 & 1.66440 & $1.6421 \mathrm{E}-06$ \\
\hline 30 & 1 & - & 2 & 1.69790 & $1.6420 \mathrm{E}+00$ \\
& $\mathrm{C}$ & 2 & 2 & 1.66530 & $8.8210 \mathrm{E}-07$ \\
\hline 40 & 1 & - & 1 & 1.84516 & $1.9173 \mathrm{E}+01$ \\
& $\mathrm{C}$ & 1 & 1 & 1.66580 & $2.0287 \mathrm{E}-06$ \\
\hline
\end{tabular}

\section{Example 3}

Let us now consider the minimization of

$$
\int_{0}^{1}\left[x^{2}(t)+u^{2}(t)\right] d t
$$

Subject to the constraint

$$
\dot{x}(t)=4 x(t)+3 x(t-0.2)+10 u(t)
$$

On using the method of multiplier, we have our results as tabulated in table 4

Table 4: Results for Example 3.

\begin{tabular}{|l|l|l|l|l|l|}
\hline $\mathrm{M}$ & Mode & Cycle & $\begin{array}{l}\text { Iteration } \\
\text { Number }\end{array}$ & $\begin{array}{l}\text { Objective } \\
\text { Functional }\end{array}$ & $\left\|\varphi\left(x_{k}, u_{k}\right)\right\|^{2}$ \\
\hline 10 & 1 & - & 4 & 1.01675 & $2.2600 \mathrm{E}-02$ \\
& $\mathrm{C}$ & 0 & 6 & 1.01940 & $1.1153 \mathrm{E}-03$ \\
\hline 20 & 1 & - & 4 & 1.01730 & $2.4196 \mathrm{E}-02$ \\
& $\mathrm{C}$ & 0 & 4 & 1.01770 & $2.2000 \mathrm{E}-03$ \\
\hline 30 & 1 & - & 5 & 1.01067 & $6.1916 \mathrm{E}-02$ \\
& $\mathrm{C}$ & 0 & 4 & 1.01797 & $2.1826 \mathrm{E}-02$ \\
\hline 40 & 1 & - & 5 & 1.00890 & $4.0186 \mathrm{E}-02$ \\
& $\mathrm{C}$ & 0 & 4 & 1.01810 & $2.0000 \mathrm{E}-02$ \\
\hline
\end{tabular}

\section{Example 4}

Finally let us consider the minimization of

$$
\int_{0}^{1}\left[x^{2}(t)+u^{2}(t)\right] d t
$$

Subject to the constraint

$$
\dot{x}(t)=3 x(t)+x(t-0.2)+7 u(t)
$$

The result is as tabulated in table 5

Table 5: Results for Example 4.

\begin{tabular}{|l|l|l|l|l|l|}
\hline $\mathrm{M}$ & Mode & Cycle & $\begin{array}{l}\text { Iteration } \\
\text { Number }\end{array}$ & $\begin{array}{l}\text { Objective } \\
\text { Functional }\end{array}$ & $\left\|\varphi\left(x_{k}, u_{k}\right)\right\|^{2}$ \\
\hline 10 & 1 & - & 6 & 1.04029 & $4.3540 \mathrm{E}-05$ \\
& $\mathrm{C}$ & 0 & 4 & 1.04145 & $6.4720 \mathrm{E}-04$ \\
\hline 20 & 1 & - & 4 & 1.04267 & $9.1310 \mathrm{E}-04$ \\
& $\mathrm{C}$ & 0 & 7 & 1.04222 & $9.5830 \mathrm{E}-06$ \\
\hline 30 & 1 & - & 5 & 1.04101 & $5.5075 \mathrm{E}-04$ \\
& $\mathrm{C}$ & 1 & 0 & 1.04350 & $3.3740 \mathrm{E}-06$ \\
\hline 40 & 1 & - & 5 & 1.04432 & $2.0580 \mathrm{E}-04$ \\
& $\mathrm{C}$ & 1 & 0 & 1.04369 & $3.2370 \mathrm{E}-06$ \\
\hline
\end{tabular}

\section{Conclusion}

In this paper, we have used the multiplier method to solve a class of optimal control problems governed by delay differential equations (with delay in $\mathrm{x}$ ). This method has a very good convergence as depicted by tables 1 and 2 above. 


\section{References}

[1]. Martin, A and Ruan, S. Predator - Prey Models with Delay and Prey Harvesting, Journal of Mathematical Biology, Vol. 43, 2001, 247-267.

[2]. Raghothama, A. and Narayanan, S. Periodic Response and Chaos in NonLinear Systems with Parametric Excitation and Time Delay, Journal of Nonlinear Dynamics, Vol. 27, 2002, 341 - 365.

[3]. Neves, K.W. and Feldstein, A. Characterization of Jump Discontinuities for State Dependent Delay Differential Equations, Journal of Mathematical Analysis and Applications, Vol. 5, 1976, 689- 707.

[4]. Wright, E.M. A Functional Equation in the Heuristic Theory of Primes, The Mathematical Gazette, Vol. 45, 1961,15 - 26.

[5]. Cunningham, W.J. A Non-linear Differential Difference Equation of Growth, National Academy of Science, U.S.A., Vol. 40, 1954, $709-713$

[6]. Volterar, V. Mathematical Theory of Hereditary Phenomenon, Journal of Mathematics Application, Vol. 7, 1928,249 - 268.

[7]. Wangesky, P.J. and Canningham, W.J. Time Lag in Prey predator Population Models, Ecology Gazette, Vol. 38, 1957, 136 - 139.

[8] Banks, H.T and Burns, J.A. Hereditary Control Problems using Numerical Methods based on Averaging Approximations, SIAM Journal of Control, Vol. 16, 1978, 169 - 190.

[9] Yorke, J.A. Non continuous Solution of Delay Differential Equations, Pro. Amer. Soc. Vol. 21, 1969,648 - 652. 